Laura Bazzicalupo. Catedrática de Filosofía Política en el Dipartimento di Scienze Politiche, Sociali e della Comunicazione de la Università degli Studi di Salerno. Sus intereses científicos son las problemáticas de las tecnologías gubernamentales, los procesos de subjetivación y los dispositivos del poder bioeconómicos y biopolíticos. Entre sus últimas publicaciones, se encuentran: Bipolitica ed economia (Laterza, 2006); Superbia. La passione dell'essere (Il Mulino, 2008); Biopolitica una mappa concettuale (Carocci, 2010); Eroi della libertà (Il Mulino, 2011); Politica. Rappresentazioni e tecniche di governo (Carocci, 2013); Dispositivi e soggettivazioni (Mimesis, 2013).

Contacto: 1.bazzicalupo@unisa.it 


\section{POPULISMO Y LIBERALISMO: LA PRETENSIÓN DE LA INMANENCIA}

Laura Bazzicalupo

Università degli Studi di Salerno

\section{POPULISM AND LIBERALISM: THE CLAIM OF IMMANENCE}

DOI: $1017450 / 160204$

Fecha de recepción $1^{\circ}$ de junio de 2016; fecha de aceptación 4 de julio de 2016. El artículo es fruto de un proyecto de investigación desarrollado en el Dipartimento de Scienze Politiche, Sociali e delle Comunicazioni de la Università degli Studi di Salerno.

\section{Resumen}

Este artículo aborda al neoliberalismo y al neopopulismo a partir de la lógica de la inmanencia biopolítica, proponiendo así su actual convivencia, en contraste con su tradicional caracterización como manifestaciones opuestas en cuanto a dinámicas de representatividad. A lo largo del texto se expone cómo del neoliberalismo se han derivado patrones de consumo e imaginarios que se relacionan con el debilitamiento de la pertenencia ideológica y las formas típicas de autoridad propias de los populismos.

\section{Palabras clave}

Neoliberalismo, neopopulismo, biopolítica, inmanencia, representación. 


\section{Abstract}

The article approaches neoliberalism and neopopulism from the logic of biopolitical immanence, thus proposing its current coexistence, in contrast to its traditional characterization as opposing manifestations in terms of the dynamics of representativeness. Throughout the text, it is exposed how of neoliberalism has derived consumption and imaginary patterns that are related to the weakening of the ideological belonging and the typical forms of authority own of the populisms.

\section{Keywords}

Neoliberalism, neopopulism, biopolitic, immanence, representation. 


\section{Una contraposición que se convierte en una imagen de espejo}

El punto de partida de este ensayo es la problemática de la clásica contraposición entre liberalismo (hoy día llamado neoliberalismo) y populismo. La palabra 'populismo' es elástica, flexible y manida: son fenómenos populistas los de Trump, de Le Pen y de Salvini, pero también de Podemos y del Movimiento 5 Estrellas. Incluso el lenguaje de Renzi es populista, así como los eslóganes del brexit, el llamamiento nacionalista de Hofer, Strache, Orbàn. Es populista Erdogan, que ahoga la forma representativa justo cuando afirma defenderla. De ahí que se trate de una palabra empleada en exceso con respecto a fenómenos diferentes. Y esto nos obliga a reflexionar sobre su mismo sentido.

Más que un concepto, hoy día el populismo parece ser una práctica de agregación cuya especificidad consiste, precisamente, en el rechazo explícito de la conceptualización, del trabajo de abstracción y mediación reflexiva que proporciona una identidad; más bien es la que Deleuze llamaría entidad operacional, una essence operatoire, una modalidad práctica de agregaciones ${ }^{1}$.

Este rasgo modal que se incorpora a la vida sin convertirla en una representación identitaria -esta es la hipótesis en la que queremos profundizar- es precisamente lo que convierte al neopopulismo en el espejo del neoliberalismo que, a su vez, está caracterizado por la coexistencia, en el ámbito de la inmanencia, de poderes heterogéneos organizados por una lógica modal, económica, ilimitadamente incluyente, selectiva, exenta de límite identitario y excluyente; unos caracteres pues que, en cambio, eran típicos de la subjetivación política moderna.

De hecho, el sujeto político al cual se refiere -el pueblo- falta, está ausente, y es improbable que se construya. El pueblo es una identidad que nace y vive junto con la lógica de la representación moderna y la reductio ad unum: algo que la política moderna construye, contaminando lo universal y particular, por medio de procesos de identificación política que se sirven de representaciones. Por eso, la teoría liberal democrática moderna se consideraba opuesta a los fenómenos populistas y a la que antes se llamaba psicología de las masas, desconfiando del valor absoluto del consenso y definiéndose por medio de reglas procedurales y de la mediación representativa, es decir, todo lo contrario al atractivo del líder carismático y luciferino.

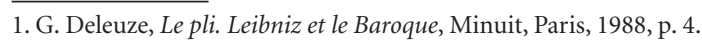


Por un lado, estaba el plebiscito populista; por otro lado, la democracia liberal representativa. Sin embargo, hoy día ambos extremos han cambiado. Hoy día, los dos polos tienen muchas relaciones y ambos forman parte de la lógica representativa, del inmanentismo estético (es decir, al mismo tiempo espectacular e inmediatamente sensorial) de formas de vida y de poder que presumen presentarse y actuar sin mediación. Este es el aspecto biopolítico del neoliberalismo.

A pesar de que también el neoliberalismo desconfíe con rencor del populismo -despolitización, por una parte gestión problem solving y por otra parte conflictividad hiperpolítica y antipolítica-, si nos remontamos a la actual disolución del dualismo representacional en el inmanentismo biopolítico, notaremos una paradójica contraposición que nos obliga a volver a considerar el populismo más allá de las categorías tradicionales. Siendo presunta y tal vez imaginaria (aunque lo imaginario hoy día ha colonizado todo lo simbólico) e inmanente a las vidas concretas en su potencia, la biopolítica pone en crisis - no solo en la teoría, sino también en la práctica- todo el régimen de la representación e identificación, basado en la trascendencia de las pluralidades en la unidad, en el cual se fundamentaba lo político.

Las consideraciones que Freud hace en la obra Psicología de las masas y análisis del yo acerca de la identificación colectiva en el líder que es mayor cuanto más débil es el proceso de identificación del individuo y la correcta formación edípica, se deben interpretar sobre la base de un proceso nuevo de subjetivación, que prefiere asociaciones, semejanzas y contagios metonímicos, en lugar de idealizaciones/identificaciones metafóricas $^{2}$. Es posedípico tanto en la formación del vínculo social que desemboca en la lógica económica/competitiva como en el vínculo político, que de la misma lógica económica adquiere el carácter ilimitado, modal, imitativo, que progresa por contagio y por precarias estabilizaciones coyunturales.

De ahí que, para pensar en el nuevo populismo del siglo XXI, sea necesario analizar la revolución cultural neoliberal que -tal y como afirmaba Foucault- es biopolítica, es decir, produce formas de vida, gobierna las mentalidades y los procesos de subjetivación ${ }^{3}$. Durante una entrevista, Margaret Thatcher dijo muy claramente que "La economía es el medio, el objetivo final es cambiar el corazón y el alma”" De hecho, las almas, las subjetivaciones son aquellas caracterizadas por una revolución profunda que cruza paradójicamente el gran estímulo expresivo, antirrepresentativo y antiautoritario de

2. S. Freud, "Massenpsychologie und Ich-Analyse (1921)", en Gesammelte Werke, Fischer Verlag, Frankfurt am Main, 1945, pp. 71-121.

3. M. Foucault, Naissance de la biopolitique. Cours au Colége de France (1978-1979), Gallimard-Seuil, Paris, 2004.

4. M. Thatcher, "Economics are the method. The object is to change the soul", en Sunday Time, 7 de mayo, 1988. 
1968, y la efervescencia de los poderes económicos y sociales del turbocapitalismo, que no aguantan ningún control que no sea la lógica modal del principio de competencia.

\section{La lógica del Todo/excepción y la lógica del no-Todo}

Los sujetos formados por la racionalidad neoliberal están afectados por el deslizamiento de una lógica identitaria hacia una modal. Es decir, disminuye la fuerza de la lógica identitaria del límite que Lacan define como lógica del Todo-excepción, la antigua lógica del significante vacío, que reúne y ordena la serie de significados sobre la base de su propia excepción ${ }^{5}$. Hablamos, pues, de la lógica de la representación y del sujeto político, que dirige el populismo clásico por ser construcción del sujeto político (aquel ruso, estadounidense, y también aquel profético, totalitario de la primera parte del siglo XX). De hecho, intentando revitalizar la política como construcción del pueblo a través del mecanismo hegemónico, Laclau moviliza precisamente la lógica de la representación del pueblo, reexaminándola desde la óptica posmoderna.

Está claro que la explosión de las diferencias y de los poderes sociales afirmativos, que se oponen a su superación, por definición singulier-pluriel, representa un ámbito resbaladizo: al perder el enganche gramsciano a la materialidad de la lucha de clase, la operación hegemónica se convierte en exclusivamente retórica. Y es inevitable llegar al nihilismo, puesto que la orientación de la inversión emotiva sobre el 'significante vacío' es incontrolable: palabras vacías como honestidad, libertad, odio a la casta, al extranjero, a los impuestos pueden proporcionar cualquier resultado...

Tal y como Lacan, Laclau sabe muy bien que el eje de la lógica Todo-excepción, es decir, la excepción unificante, el nombre del Padre, no está caracterizado por la erosión deconstruccionista. Sin embargo, por mucho que se limite a una combinación de vacíos, faltas, aplazamientos (la totalidad fracasada de lo social, la nunca exhaustiva representabilidad del sujeto, el límite entre significante y significado, el excedente de la subjetividad respecto de la marca identitaria, la plenitud imposible del objeto a, que empuja la inversión política...), a pesar de todo eso, la representación sigue siendo un pasaje obligado para cualquier proceso de subjetivación ${ }^{6}$.

5. J. Lacan, Le Seminaire. Livre V. Les formations de l'inconscient (1957-58), Seuil, Paris, 1998.

6. E. Laclau, On Populist Reason, Verso, London, 2005; Id., Identity and Egemony. The Role of Universality in the Constitution of Political Logics, in J. Butler, E. Laclau, S. Žižek, Contingency, Hegemony, Universality. Contemporary Dialogues on the Left, Verso, London, pp. 44-89; cfr. S. Critchley, O. Marchart (eds.) Laclau. Aproximaciones críticas a su obra, Fondo de Cultura Económica, Buenos Aires, 2008. 
¿Sigue ocurriendo esto hoy día? ¿Es verdad que las subjetividades múltiples que se 'presentan' en la escena política se prestan para una síntesis/articulación?

Parece que, en el esquema de Laclau, algo no funciona. Por un lado, Laclau detecta el estrecho enlace del populismo con la realidad neoliberal posideológica (dando paso, por ende, a la retórica y a la superación del marxismo); por otro lado, no capta del neoliberalismo la fuente específica y revolucionaria. No es suficiente vaciar la hegemonía de Gramsci del enganche ‘objetivo’ y material: la revolución profundiza más en la cuestión.

La que desaparece es la misma lógica de la representación, de la reducción de la pluralidad al significado unitario, a la totalidad identitaria o proyectiva -imposible, pero necesaria- que se basa en una excepción del orden (y, tal y como nos recuerda Agamben, en la exclusión). Simplemente, aquella no es la lógica de nuestro tiempo, la lógica del neoliberalismo, pues ya no es la lógica del nuevo populismo. Ni identidad, ni proyecto unitario. De ahí que - puesto que la racionalidad neoliberal convierte a la coexistencia incoherente de lógicas heterogéneas en su punto fuerte- nos encontremos con fenómenos populistas de tipo moderno e identitario o con señales identitarias en los populismos nuevos, pero el punto crítico es la inestabilidad, lo ilimitado que los caracteriza.

Nuestra tesis es que la revolución neoliberal -espejo deformante del gran ataque de 1968 contra la lógica de la representación y de la autoridad, en nombre de los poderes sociales y de las vidas concretas- lleva al eclipse de la lógica metafórica/simbólica del nombre que, por medio de la excepción, representa la totalidad de las diferentes preguntas, a favor de una lógica del no-Todo, del no-límite y de la no trascendencia simbólica: lógica de la inmanencia biopolítica, indeterminada y metonímica.

¿Qué ha ocurrido?

Se enfatiza el carácter contingente de un significante cualquiera (aquel que encarna de forma contingente la función-ficción de la excepción) vacío, inconsistente: la tensión Todo-Excepción -que Laclau lleva adelante con un esfuerzo voluntarista y retórico- ya no logra poner en orden el sistema que desemboca en la dispersión incoherente de los elementos: la vida y su devenir múltiple y pulsional.

En Encore, Lacan da paso a esta inexistencia/inconsistencia: el confín de lo simbólico se deshilacha, ya no define lo interior y lo exterior, sino que genera múltiples puntos específicos, puntos de agregación simbólica precaria ${ }^{7}$ (lo que sorprende es que son las mujeres -figuras con una diferencia exenta del límite castrante- las que son definidas a través de esta relación con el otro inconsistente, pas tout, este Real del no-Todo). El plan

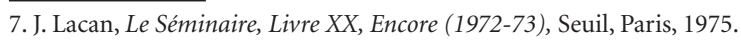


de la vida -que es no-Todo porque no es totalizable, ilimitado-genera singularidades indeterminadas, exentas de subjetivación acabada. De hecho, un sistema no-finito no se produce por 'negación', por interdicción, por contraste, sino por la indeterminación abierta que crece sobre sí misma. Es un sistema abierto de diferencias que varían por imitación, contigüidad y asociación, de forma horizontal y contingente en un continuum que sigue la dinámica del prójimo y no de lo propio y de la identidad.

Es, precisamente, esta la forma de agregación floja que caracteriza al sistema gubernamental neoliberal, que se aleja fuertemente de las formas modernas de racionalidad política y de los procesos de subjetivación modernos, basados en la ley y en el deseo. Más que la neurótica alternación de las agregaciones hegemónicas de Laclau, nos encontramos con colocaciones flexibles, lábiles, inacabadas, con agregados en torno a un punto de trascendencia precario: un acontecimiento chocante, una imagen, un gesto enseguida difundido y enseguida imitado, en la red; una máxima normativa que emerge de preferencias y humores compartidos, un eslogan cautivador, fácil, ejemplificador; en un circuito estrechísimo de la vida a la vida, sobre el cual nos tendremos que reflejar porque en su dispersión libertaria, inmanente a sí misma, está expuesto a la máxima heteronomía gestional a través de sistemas evaluativos jerarquizantes. Se trata, pues, de agregaciones inaccesibles a una subjetivación general, a un significante universal: la mujer no existe. Existen las mujeres. Mejor dicho, las posiciones femeninas de la diferencia.

La falta de límite no solo implica cierta distancia del discurso simbólico que se desvía hacia el simulacro, sino también una relación especial con la jouissance, el mítico e impersonal deseo puramente afirmativo de Deleuze, con un más, un encore (aquí nos sobreviene la pulsión aumentativa del capitalismo: ¿plus gozar como plus valor? Se trata de una intimación al empowerment, al incremento productivo para todos y en todos los ámbitos de la vida). La vida no mediada se conforma en exceso de forma pulsional y automática. Este ya no es un síntoma, sino la forma de vida de nuestro presente: perversa-psicótica, literal y sin inconsciente, que no tiene distancia crítica.

Desconectada de la territorialización identitaria, la gubernamentalidad neoliberal es un modus aplicable a cualquier móvil o deseo. Es económica, no tanto en el sentido de que la economía es el dominio prevaleciente sobre todos, sino en el sentido de una lógica organizacional, que de lo económico adquiere la imposibilidad de una definición a priori deductiva y totalizante, a favor de un estímulo imitativo y competitivo, que funciona por asociación y estándares estadísticos. Económico no es el choque, el límite, la sublimación del deseo (mecanismo que sigue valiendo en el caso de las teorías neohegemónicas), sino el juego de la repetición y reproducción valorizada de forma 
diferencial en la base de indicadores que emergen de forma contingente desde abajo, del contagio imitativo por asociación/variación. Si hay trascendencia simbólica, esta es lábil, simulada.

Como racionalidad absolutamente posideológica, el neoliberalismo desmantela la entidad/identidad pueblo y su igualdad abstracta, refiriéndose a grupos de vivientes desiguales por potencialidades y riesgos -las poblaciones: agregaciones bioestadísticas gobernables de forma diferencial; poderes sociales en concreto desiguales y que compiten entre ellos, que sería equivocado totalizar en un proyecto unitario, solidario. Más que anárquico, el sistema de combinaciones e interdependencias de cada vector de poder y de elección es acéfalo- sin un sujeto político soberano y responsable. Sin embargo, es capturado y reducido a un orden por medio del principio simil-biológico, simil-darwiniano de la competencia, justo para formas de vida imitativo-asociativas, principio de orden sin trascendencia, inmanente a las vidas mismas.

\section{Nuevo populismo inmanentista}

Esta lógica inmanentista y vitalista, contraria a la mediación y a la trascendencia institucional afecta de sobremanera al fenómeno populista, que ya no es el viejo populismo constructor del pueblo a través de una identificación irracional, sino que es fuerte. Las diferencias son biopolíticas en el sentido afirmativo del término, biopotencias, potencia de autogestión, negación del poder, de la representación: manifiestan de manera directa y de inmediato su propia elección, deseo, insatisfacción. Estas prácticas de esternización, junto con el rechazo de la mediación conceptual, entendida como traición de la vida verdadera, se centran en la presentación de sí, en la presencia directa (aunque en su mayoría virtual, de streaming), y temporalmente no mediada. De ahí que se trate más de presencia que de representación.

Parece que el hecho mismo de estar, de exhibir sus propios cuerpos vivientes y las caras filmadas en streaming, le asegura la consistencia y autenticidad al mensaje políti$\mathrm{co}^{8}$. El plan de consistencia y coexistencia inmanente se presenta como vida en vivo, de alguna manera impersonal, biopolítica que, mientras se manifiesta, es verdadera, revolucionaria y popular, y deja en el silencio de la hipocresía y de la mentira las formas de la mediación, los ritos de la política y sus envolvimientos.

8. J. L. Villacañas, Populismo, La Huerta Grande, Madrid, 2015. 
El frente de división, el confín tan importante para la política, no se basa en dos diferentes visiones de repartición del poder, sino en la naturalidad del viviente que es como es. Como tal, muestra y manifiesta el descontento, el miedo -presumiendo que exhibirlos signifique justificarlos-. Paradójicamente, este hiperrealismo convierte en porosos y lábiles a los frentes que dividen e intercambian las posiciones políticas.

Hemos hablado también de los populismos gubernamentales. En este caso, mostrar el plan de consistencia de la vida como intrascendible significa dar por descontado e indiscutible el orden económico organizacional, el principio de competencia: la que Wendy Brown define como la naturalización del capitalismo9 ${ }^{9}$ Solo se puede secundarlo, tal y como se secunda la verdad y la vida, no hay otra posibilidad.

En ambos casos, solo en apariencia diferentes, el ser de la vida contiene en sí su propia verdad: manifestarla, afirmarla de inmediato es lo más importante. La crisis del dualismo simbólico da paso al mundo de la presencialización físico-biopolítica, pero también y de manera paradójica a la hiperrealidad de los simulacros, que no remiten a nada. El imaginario neoliberal disuelve, en la inmanencia de las emergencias por gestionar o en la presencialización directa, todo proyecto y representación moderna. Así que desvanece un punto de posible torsión sintomática, una parte de los que no tienen parte que, a pesar de estar dentro del sistema, no vale; este era el pueblo de la democracia radical, de Ranciere o de Žižek, que se sirve de este elemento excesivo, pues de este fantasma para la lucha de emancipación.

En cambio, en este caso el sistema se presenta como si ya no excluyera nada. No excluye ni siquiera el exceso, es más, lo considera como su fuerza motriz, cambiando constantemente los límites. A la exclusión -concepto central de la representación y de su hueco estructural, pero fecundo para el cambio político democrático- le sucede la inclusión vitalista -all inclusive - que da lugar a la similitud horizontal e indeterminada, dejando que los criterios de la selectividad sean indeterminados.

El debilitamiento de la pertenencia ideológica destaca un tipo de influencia no autoritaria/autorizada, sino -tal y como emerge de los estudios de Tarde sobre lo público- orientada por los mecanismos de asociación e imitación típicos de las elecciones de consumo que se extienden a las elecciones políticas ${ }^{10}$. El marketing electoral y la comunicación política insisten en lo que, estéticamente (es decir, sensiblemente y de forma espectacular), 'atrae': el viviente concreto, la personalidad, el gesto y el estilo del personaje

9. W. Brown, "Neoliberalism and the End of Liberal Democracy", en Edgework. Critical essays on knowledge and politics, Princeton University Press, Princeton, 2005, p. 40.

10. G. Tarde, La logique sociale, Alcan, Paris, 1895. 
que se propone. Al imponerse sobre la visibilidad del viviente, la elección es 'superficial', no moviliza el mecanismo de idealización, sino que insiste en los rasgos visibles-sensoriales: superficie estética exasperada por la espectacularización de la política.

Y la participación populista se convierte en literalmente 'superficial', exteriorizada en la misma práctica y en el contacto próximo (aunque a través de redes sociales). También el antagonismo que puede intercambiar a las partes es superficial, emotivo, sensorial y retórico. La misma creencia, matriz de la función autorizada-normativa, se mueve de forma metonímica, imitativa por yuxtaposición, sin grandes metáforas que determinen la producción positiva del sentido. Más similar al crédito (la fiabilidad económica) que a la fe.

El plan de inmanencia determina el ocaso de los partidos, organizadores de mediación y de proyecto, dejando emerger del juego de las asociaciones-imitaciones al líder populista. Está claro que este no vuelve a producir la identificación paterna, típica de todas las formas de 'autoridad': el eje se desplaza de los contenidos que idealizan la credibilidad personal del líder, siendo viviente que se 'autovalora', capital humano, como todos, alguien que, por el weberiano 'don de la gracia' y por las dotes de creatividad es evaluado, en una perspectiva biopolítica, en la base de las cualidades medianas-mediocres que permiten, por lo general y por lo visto, 'tener confianza', reconocerse en el estilo visible del vestuario, o en la tranquilizadora semejanza del lenguaje coloquial, que posibilita su imitación; estética que se basa en el análisis ponderado de una disposición, por ejemplo, en la tutela de los derechos del trabajador. Es la excepcionalidad de la lógica del todo/excepción que deja lugar al no-todo de la relación de similitud.

La capacidad personal y el crédito en las prestaciones esperadas funciona como única y flébil brújula en un mundo complejo y atonal, sin una orientación identificable, contra el que hay que luchar; un mundo modelado en el mercado como cruce inestable de las expectativas fiduciarias de todos los competidores, del cual no se entiende el sentido. Nadie sabe interpretarlo y convertirlo en previsible, cualquier creatividad política no adaptiva está desacreditada. De esta impotencia estructural de conocer la evolución de las cosas -que, además, legitima los dispositivos de emergencia problem solving que suspenden las vacilaciones de la deliberación democrática- procede la solución resentida y privativa que, para Rosanvallon, reaviva la homogeneidad imaginaria del pueblo, solo y exclusivamente en su dimensión negativa, opuesta ${ }^{11}$.

No hay un horizonte proyectivo que no sea visible ni presente, sino sería divisorio e indecidible. Solo hay programas de adaptación óptima y malestar populista: el uno

11. P. Rosanvallon, La contre- démocratie, la politique à l'age de la défiance, Seuil, Paris, 2006. 
es el espejo del otro. La creencia impuesta en el plan de la inmanencia tiene una duración breve, no va más allá de la visibilidad directa: lo que no se ve, suscita sospecha. El crédito personal parece ser más importante respecto de las razones constructivas de agregación.

La imitación agrega el descontento, pero elimina las divergencias que emergerían con respecto a un programa, por ejemplo, político-económico. El grupo adquiere una identidad reactiva, coyuntural, agregada por un estímulo y puede disgregarse con rapidez y sin problemas. Se destaca su rasgo específico, su razón de ser: la hostilidad hacia la representación misma, la mediación que, en su movimiento dialéctico, es invisible, de ahí que no sea creíble. Es mejor desplazar el patrimonio de creencia sobre un cuerpo viviente lo más posible similar a sí mismo.

Una subjetivación reactiva presenciada en el evento coincide con este: se consume en una expresividad política que, gracias al líder, busca el camino más breve para ponerse en práctica. El hecho de aparecer y de presentarse -la dimensión estética se sustituye con el proceso ético-dialéctico- reemplaza la representación, ofuscando aquella diferencia temporal y mediática necesaria para la política proyectiva.

Está claro que este cortocircuito reactivo mantiene un nivel de politicidad injustamente negado por los diagnósticos liberal democráticos; incluso sería más correcto decir que genera un superávit de politicidad porque, denunciando el déficit de representatividad de las élites, custodia de manera contradictoria una necesidad democrática que no se puede subestimar: la exigencia de mayor participación política y de mayor representatividad que el populismo exige y que, luego, traiciona con clamor.

Taggart sostiene que el populismo es el medio para medir el buen funcionamiento del sistema político representativo ${ }^{12}$; tal vez incluso sea un indicador de la erosión de la lógica representativa que se incorpora en una presencialidad estética. El nuevo populismo no representa, presenta; no media, es inmediato, tanto en la versión en la que emerge un líder como en las experiencias de multitud participativa. Reivindicando la concreción antiintelectualista de la vida verdadera, la encarna en una persona física viviente cualquiera, similar/asimilable, contagiosa, imitada y variada infinitamente. pasar de los muchos -vivientes, singulares, concretos y presumiblemente diferentes- al uno no puede sino conducir a un unicum que es todos, uno como todos, con la misma rabia, la misma debilidad, la misma potencia amenazadora, tal vez más expresiva y mejor expresada.

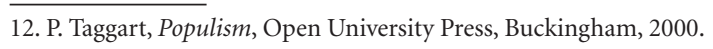


La voz del líder presentifica resquemor y ansiedad de todos y de cada uno pero, al mismo tiempo, imposibilita ver las diferencias de los rostros; las exhibe en su presunta inmediatez, oponiendo a las abstracciones institucionales un mundo en el que se ve todo, todo es transparente, abierto como la que Beppe Grillo llama caja de sardinas, y visible en el cuerpo ostentado del líder y de los participantes que, por el mismo hecho de exhibirse, confirman la confianza en su propia autenticidad expresiva. Así que todo aparece, todo es visible. ¿Qué es lo que no aparece? ¿Qué es lo que no es visible?

\section{La visibilidad y la apariencia}

En esta exhibición de semejantes no se ve todo. Se borran las zonas de sombra o que harían sombra, la diferencia de los proyectos y de las situaciones en una realidad que conocemos como jerarquizada y desigual. Lo que se pone en escena es lo que, paradójicamente, Rancière llama la revocación de la esfera de apariencia del pueblo. La comunidad es, en esa identificación, ininterrumpidamente presentada a sí misma. Para este autor, el pueblo ya no será desigual, incalculable, irrepresentable. Siempre estará presente y totalmente ausente, comprometido por completo en una estructura de lo visible, donde se ve todo y donde ya no existe un lugar relacionado con el hecho de aparecer ${ }^{13}$. Cuando falta la representación política siempre incompleta del pueblo, falta la posibilidad de la parte antagónica/subalterna de 'aparecer' realmente, es decir, de irrumpir en el doble nivel de la escena. La extrema y total visibilidad destruye "la apariencia y sus potencialidades"14. El régimen del omnivisible no corresponde a la liberación de la apariencia. Por lo contrario, implica perderla. El mundo de la visibilidad global predispone una realidad en la que la apariencia no puede manifestarse ni producir sus efectos de duplicación y de división. Esto ocurre porque la apariencia -sobre todo la apariencia política- no es lo que esconde la realidad, sino lo que la duplica, introduciendo en ella elementos conflictivos. El hiperrealismo populista coincide con la pretensión de que la visibilidad de la vida es suficiente para demostrar su complejidad. Así que elimina las conflictividades presentes en la representación y en la identificación, dificultando el trabajo de la crítica y de la posibilidad de reconsideración política del orden existente.

Por lo tanto, por una parte, el populismo se desarrolla en el ámbito cultural de la gubernamentalidad neoliberal, expresando su rechazo de las síntesis institucionales, ad-

13. J. Rancière, La mésentente, Galilée, Paris, 1995, p. 116. 14. Ibid. 
quiriendo su lógica de la ilimitación y de la inmediatez; por otra parte, presenta cuerpos vivientes, sin espesor y doblez, pues que coinciden con ellos mismos. Esforzándose por mantener juntos la exigencia democrática de autogobierno y participación con la manifestación de un sí unitario y no conflictivo en la persona del líder o de los activistas, exige más política y conflictividad, anulándolas al mismo tiempo. En este movimiento contradictorio, casi sin lógica representativa, está su límite.

¿Qué ocurre cuando el pueblo coincide con su presentación y visibilidad total, cuando una multitud coincide consigo misma, con su propia voluntad sin conflictos y antagonismos internos? La presentificación quita toda ambigüedad, todo fantasma y conflicto potencial dentro de la fotografía de grupo. Si el desacuerdo es visible, esto depende de lo que queda del doblez y de la 'mentira' representativa que traiciona a la misma multitud (y a su líder), así que está fuera del grupo. Está fuera del pueblo.

Para concluir, podemos decir que las mónadas neoliberales se asocian entre ellas, se contagian horizontalmente por contacto, por semejanza, metonímicamente; forman un público que participa activamente, que está interconectado, al que se incorpora y se plasma el mensaje del actor líder. La relación de identificación está afectada por un gran cambio: de la alienación en un líder que representa un ideal, un mito, una misión, llegamos a una influencia virtual, vívida pero lábil. Los individuos mantienen su narcisismo, su imaginario neoliberal de autorrealización y autogestión. El líder y los activistas son, representan una corporeidad común, por semejanza. El descontento inexpresado e irrepresentado se les manifiesta a todos, identificándose fácilmente en los deseos y resquemores de todos. No hay sublimación, ni alienación, ni sacrificio de las diferencias en la identidad unitaria del pueblo.

No hay plebe que se abandona al mito del líder. Es el populista el que adquiere credibilidad porque imita, secunda las imágenes de lo público que emergen de la red, de los sondeos que representan estadísticamente lo que es, lo que la gente dice, que la red afirma o exige, sin sombras, sin ambivalencias ni fantasmas. El jefe -si está- no es un padre, un líder superyó que conduce a la tierra prometida, sino un hermano más afortunado, más dotado, más astuto, incluso divertido; tal vez un hermano que hoy, en una larga crisis sin solución plausible, se haga cargo de poner de manifiesto la conflictividad, el desacuerdo, pero al mismo tiempo los vacía, negándoles la articulación de un proyecto alternativo hacia el que encaminarse. Su voz protesta o afirma. Y no hay rasgo umbrátil en su afirmación. Parece hacerse cargo de la mission de la democracia pero, en la lógica de la inmanencia impuesta sobre el presente y sobre la presencia, representa de forma amorfa el "mundo tal y como es", el mundo que 
autoproclama auténtico contra la falsedad de los juegos de poderes. En esta hipervisibilidad, no solo ignora las disimetrías, las complicaciones y el desacuerdo, sino que asimila el descontento y lo para sin crear alternativas, sin que la mediación reflexiva actúe para modelar lo social.

No hay proyecto político, aunque el viento impetuoso de esta mezcla de desconfianza y credulidad, de cinismo y confiada confianza en la voz de uno como todos, arrastra las frágiles instituciones; y esta es la política, arriesgada, pero es política.

Traducción del italiano de M. Colucciello 